\title{
Yüksek Çözünürlüklü Yersel Lazer Tarama Verilerinin Filtrelenmesi ve Filtrelemelerin Heyelan İzlemeye Etkisi
}

\author{
Mustafa Zeybek ${ }^{1,{ }^{*}}$, İsmail Şanlıoğlư ${ }^{1}$, Aşır Genç ${ }^{2}$ \\ ${ }^{1}$ Selçuk Üniversitesi, Mühendislik Fakültesi, Harita Mühendisliği Bölümü, 42250, Konya. \\ ${ }^{2}$ Selçuk Üniversitesi, Mühendislik Fakültesi, İstatistik Bölümü, 42250, Konya. \\ Özet
}

Doğal afetlerin izlenmesi ve araştırılması zararlarının önüne geçilmesindeki en önemli çalışmalardan bir tanesidir. Bu çalışmada, Yersel lazer tarama (YLT) tekniklerinin heyelan izleme çalışmalarında kullanımı ve elde edilen verilerin işlenmesi ve sonuçlarının irdelenmesi yapılmıştır. Araştırmalar, Orta Toros Dağlarında meydana gelen bir heyelan bölgesi üzerinde yapılmıştır. Bölge içinde yapılan önceki çalı̧̧malar irdelendiğinde 5 m'ye ulaşan deformasyonlar oluşmuştur. Bu makalede, yersel lazer tarama verileri içerisinde otomatik olarak filtreleme; yeryüzü üzerinde ă̆aç ve diğer objelerin filtrelenmesi ve saylsal yükseklik modeli (SYM) elde edilmesi, bu modeller sayesinde arazi yüzeyinde yükseklik bileşenlerinde meydana gelen değişimlerin araştırılması ve filtreleme algoritmalarının analizlere olan etkisi araștıılmıștır. Bu araştırma için İlerleyen Morfolojik Filtreleme (IMF) algoritması kullanılmıștır. Bu filtreleme algoritması ile nokta bulutları otomatik olarak yer ve yer harici olmak üzere iki adet filtrelenmiş veri elde edilmiştir. SYM elde etmek için yalın yeryüzünün kullanılmast modelin gerçek yeryüzünü yansitması yüzeyde oluşan deformasyonların belirlenmesiyle doğrudan etkilidir. Sonuç olarak filtrelenmeden kullanılan nokta bulutları verileri bölgesel anlamda yapılan analizlerin yanlış yorumlanmasına sebep olabileceğinden dolayı ağaç, obje, araç ve ev gibi bitki örtüsünün ve insan yapılarının filtrelenmesi gerekmektedir. Filtreleme yapılan karșlaștırma analizleri daha kolay yorumlanmistır. Modellerin karşılaştırılmasında farklı dönemlere ait bitki örtüsündeki değişimler otomatik filtrelenmiş ve heyelan hareketleri yapay bozulmalardan arındırllarak yorumlanmıştır.

\section{$\underline{\text { Anahtar Sözcükler }}$}

Heyelan İzleme, Yersel Lazer Tarama, Nokta Bulutları, Filtreleme

\section{Filtering Data of High-Resolution Terrestrial Laser Scanner and Effects of Filtrations on the Landslide Monitoring}

\begin{abstract}
Monitoring and investigating natural disasters is one of the most important works for decreasing damages and preventing losses. In this study, using Terrestrial Laser Scanning (TLS) techniques for landslide monitoring studies, processing data obtained from these techniques and evaluating the results were performed. Research was carried out on a landslide zone which occurred in the Middle Taurus Mountains. When previous studies were examined, deformations reaching up to $5 \mathrm{~m}$ were formed in the region. In this article, automatic filtering of terrestrial laser scanning data, filtering of trees and other objects on the earth and acquiring digital elevation model (DEM) and by means of this model, assessing changes occurring in the elevation components on the land surface and the effect of filtering algorithms on analysis were investigated. Progressive Morphological Filtering (PMF) algorithm was used for this research. Point cloud filtering algorithm has automatically obtained two filtered data as the ground and the non-ground. Using the real surface ground models of the earth to obtain DEM model's reflection of real earth surface has a direct impact on determining the true surface deformation. In conclusion, things such as trees, objects, vehicles, houses, man-made structures and vegetation must be filtered out of data because analysis in a regional base may cause misinterpretation without filtered point cloud data. The results revealed that the filtered comparison analyzes were evaluated easier. In addition, changes in plant cover in different periods for the comparison of models has been automatically filtered and the landslide movements have been interpreted with purifying from artificial distortion.
\end{abstract}

$\underline{\text { Keywords }}$

Landslide Monitoring, Terrestrial Laser Scanning, Point Cloud, Filtering

\section{Giriş}

Jeodezinin en önemli görevlerinden birisi de doğal afetlerin izlenmesi ve gerekli önlemlerin alınmasında zaman kazanımı sağlamasıdır. Bu nedenle heyelan, deprem, su baskınları vb. doğal afetlerin önceden kestirimi, afetlerin oluşumu ve modellenmesi gerekmektedir. Jeodezik çalışmalar, teknolojik gelişmeler doğrultusunda GPS (Küresel Konumlama Sistemi) veya GNSS (Küresel Uydu Seyrüsefer Sistemleri) ile devrim atlamıştır. 20. yy sonları ve 21. yy 
başlarından bu yana LiDAR (Light Detection and Ranging) teknolojisinin Jeodezik uygulamalara başlanması heyelanların izlenmesine katkı sağlamıştır.

LiDAR teknolojisi obje yüzeyinden yansıyan yüksek frekanslı kızılötesi 1şı̆̆ın algılayıcıda (Lazer tarama cihazı) kayıt edilmesi ile obje ve tarama cihazı arasındaki mesafenin belirlenmesi prensibine göre çalışmaktadır (James vd. 2007). Çevre ve doğal afet izleme çalışmalarında yersel LiDAR, hava LiDARı, mobil LiDAR ile literatürde pek çok çalışma ve araştırma yapılmıştır (Kasperski vd. 2010; Brodu ve Lague 2012; Oppikofer vd. 2012; Pirotti vd. 2012; Barbarella ve Fiani 2013; Zeybek ve Sanlioglu 2015; Zeybek vd. 2015)

Genellikle Sayısal Yükseklik Modeli (SYM), yersel tekniklerin yanında hava LiDAR (HL) ve uzaktan algılama teknikleri ile yapılmaktadır. Fakat yüksek doğruluk, yoğunluk ve karmaşık alanlarda YLT uygulamaları daha pratik ve uygulanabilirliği yüksektir. Geçmişte analitik fotogrametri ile geniş alanların yüksek doğrulukla topoğrafik bilgilerinin alınmasında en temel teknik olarak kullanılmıştır. Manuel olarak yüzey özellikleri seçilir ve enterpolasyon yöntemleriyle SYM'ler üretilirdi. Günümüzdeki teknikler ise (InSAR, HL) yüksek seviyede otomatikleştirilmiş ve kolaylaştırılmıştır. İlgilenilen alanlarda yoğun veriyi kısa zamanda elde edilmesi yeni tekniklerin en çok benzer özelliklerinden biridir. Önceden kullanılan tekniklerle karşılaştırıldığında yoğun veriler üzerinden SYM'lerin üretilmesi verilerin elde edilmesinden sonra işleme tabi tutulmaları gerekliliği ve yalın yeryüzünün elde edilmesi zorunluluğu vardır. $\mathrm{Bu}$ nedenle yoğun verilerden bilgi çıkarımı için filtreleme, sınıflandırma, enterpolasyon vb. gibi özellik çıkarımları yapılmalıdır.

Bu çalışmada yersel lazer tarama (YLT) sistemleri ile heyelan öncesi ve heyelan sonrası yapılan çalışmalarda elde edilen ham verilerin bitki örtüsü, trafik işaret levhaları, ağaçlar vb. gibi yer üzerinde bulunan objelerin sayısal yükseklik modeli üretimi öncesinde filtrelenmesi ve farklı periyotlar arasındaki heyelan hareketleri incelenmiştir.

\section{2. Çalışma Bölgesi}

Çalışma bölgesi Konya Merkezine $133 \mathrm{~km}$ mesafede ve güneyinde yer alan, orta Torosların kuzey yamaçlarında meydana gelen alanda çalışmalar yapılmıştır (Şekil 1). Heyelan oluşan yamaçların yönleri kuzey-batı yönündedir. Kış dönemlerindeki yoğun yağışlar ve bahar yağmurları bu bölge heyelanları için etkili tetikleyiciler arasındadır. Bölgede oluşan heyelan hareketleri farklı gruplarda sınıflandırılabilir. Heyelan hareketleri az hareketli bölge ve çok hareketli bölge olarak sınıflandırılmıştır. Genellikle heyelan sınırları arazi gözlemleriyle görülebildiğinden sabit bölgelerin tanımlanması kolaydır. Heyelan alanı daha önce bilimsel çalışmaya konu olmadığından detaylı bilgiler yalnızca Maden Tetkik Arama (MTA) ve Türkiye Cumhuriyeti Karayolları (TCK) kurumlarından elde edilmiştir. Yerel halkın bilgisine göre bölgede oluşan heyelan uzun yıllardır sürmekte ve bölgede karayolu, sulama kanalları ve tarım alanlarına belirli dönemlerde zararlar vermektedir.

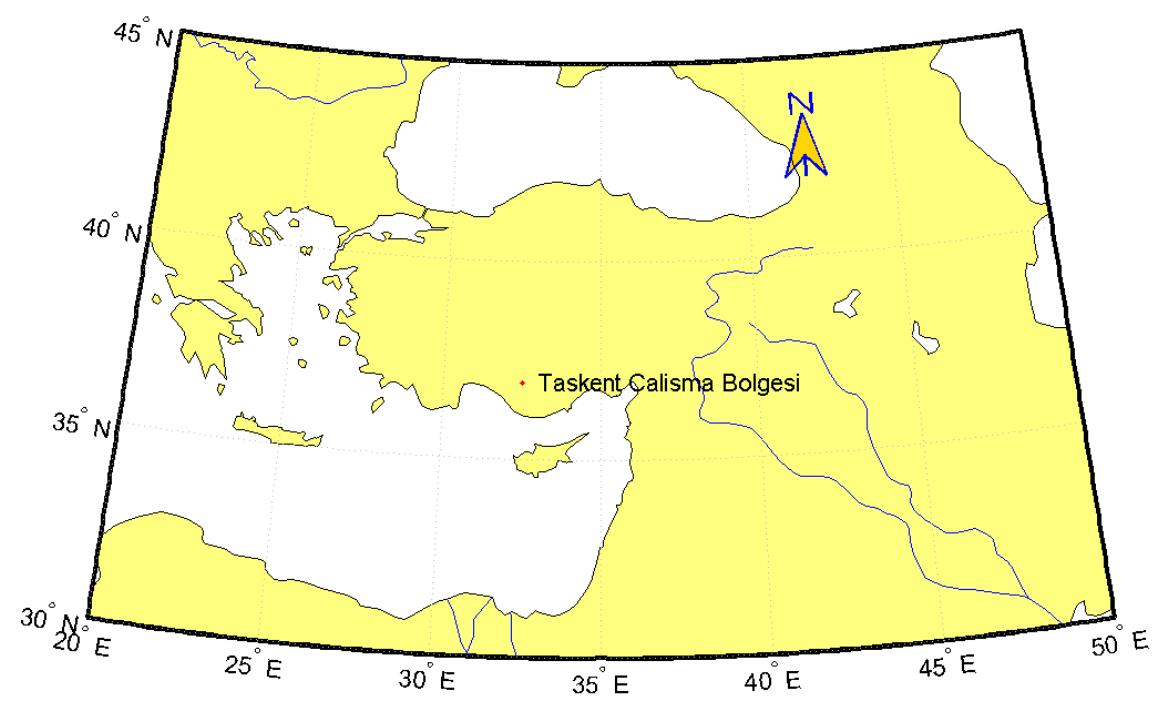

Şekil 1: Taşkent çalışma bölgesi yer bulduru haritası.

\section{Materyal ve Yöntem}

\subsection{Yersel Lazer Tarama Sistemi ve Nokta Bulutlarının Verilerinin Toplanması}

Üç boyutlu (3B) optik ölçme sistemleri genellikle iki grup altında tanımlanmaktadır: bunlar

- Lazer ışınının havada aldığı zamanın belirlenmesi prensibi

- Üçgenleme metodu 
olarak sınıflandırılır. Işın dalgasının belirli bir ivme ile havada aldığı yol, zaman ve ışık hızı ile belirlenir. Üçgenleme yöntemi ise belirli bir açı ile gönderilen ışınların yüzeyden çarpıp kosinüs kuralına göre algılayıcıya geri dönmesiyle çalışan sistemler olarak karşımıza çıkmaktadır (Şekil 2). Uçuş zamanlı lazer tarama sistemleri genellikle orta ve uzun menzilli çalışmalar için kullanılırken üçgenleme prensibi ile çalışan tarayıcılar genellikle 5m'ye kadar olan yakın menzilli tarama çalışmalarında kullanılmaktadır. Bu sınırlandırma nedeniyle haritalama ve izleme gibi çalışmalarda uçuş zamanlı tarayıcılar tercih edilmektedir (Vosselman ve Maas 2010).
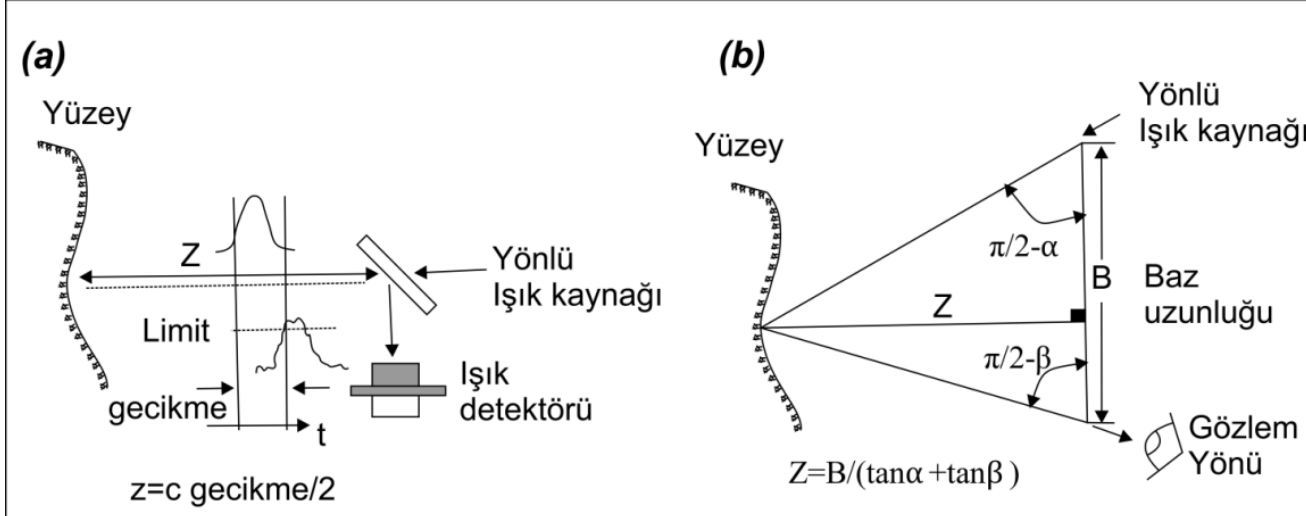

Şekil 2: 3B’ lu yüzeyin optik metotlarla ölçülmesi a) Işık hızı b) üçgenleme (Vosselman ve Maas 2010).

Bu çalışmada kullanılan lazer tarama sistemi uçuş hızı prensibini kullanan Optech 3D tarama cihazı kullanılmıştır (Şekil 3). Tarama cihazı kontrolü laptop üzerinden tarama ile ilgili parametreler girilerek yapılmıştır. Bataryaların tarama ömürlerinin kısa olması nedeniyle jeneratör kullanılmıştır. Tarama cihazı 100m'lik mesafede $\pm 7 \mathrm{~mm}$ uzunluk ve $\pm 80 \mu \mathrm{rad}$ açı ham doğruluk değerlerine sahiptir. Cihazla ilgili detaylı bilgi (http://www.teledyneoptech.com/wpcontent/uploads/ILRIS-Spec-Sheet-140730-WEB.pdf) sitesinden erişilebilmektedir.

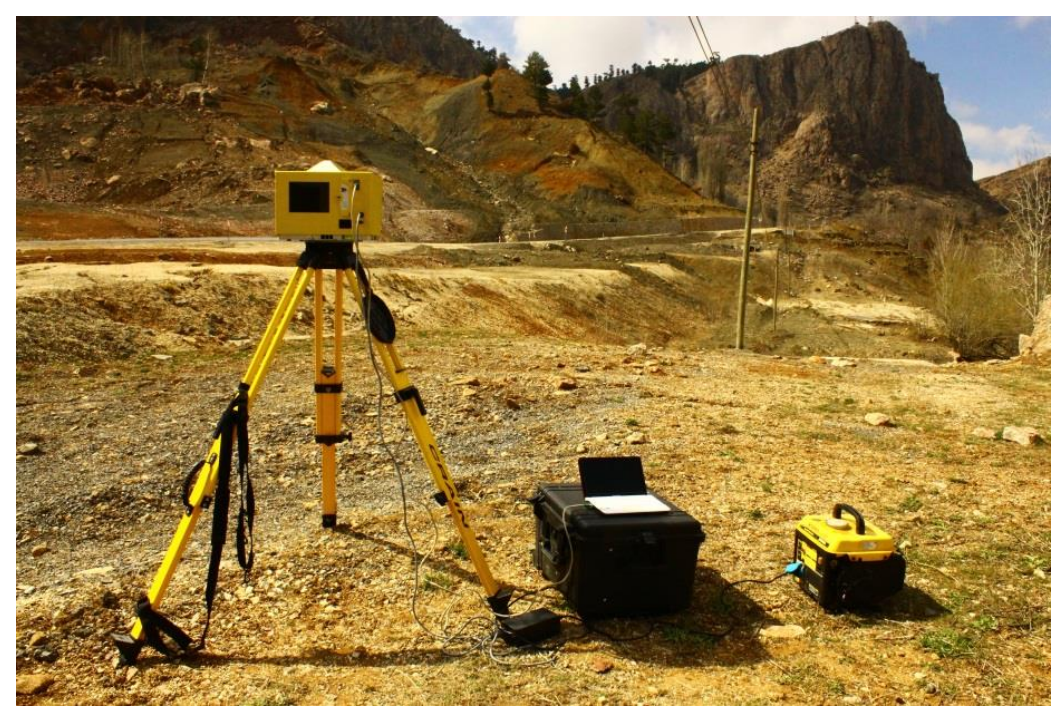

Şekil 3: Yersel lazer tarama cihazı, kontrol ünitesi (laptop), jeneratör.

Heyelan çalışması için iki farklı zamanda ölçüm kampanyası düzenlenmiş, bu makalede iki farklı döneme ait ölçümlerin değerlendirilmesi yapılmıştır. İlk ölçüler Eylül 2012 dönemine, ikinci ölçüler ise Mart 2013 dönemine aittir. Deformasyon çalışmaları için zaman aralıkları önemli hususlar arasındadır. Bu nedenle bölgeyle ilgili yapılan daha önceki çalışmalarda kış dönemi sonrası hareketlerin başladığı tespit edilmiştir. Sıfır (ilk) periyot ölçmelerinin zamanı ve değerlendirilecek olan ikinci periyot zamanı arasında 6 aylık zaman aralığı bulunmaktadır. İlk ölçmelerde lazer tarama cihazı ilgili çalışma alanının tamamını kapsaması açısından farklı noktalara kurularak ortalama 15 ile 20 dk'lık ölçüm süreleriyle birlikte toplam 5 farklı noktaya cihaz kurulumu yapılmıştır. Bu kurulumlarda farklı görüş açısı ile yaklaşık $180^{\circ}$ görüş ve $80^{\circ}$ düşey görüş açısı ile taramalar yapılmıştır. İkinci ölçmelerde 6 farklı noktaya cihaz kurulumu yapılmıştır. Ölçme süreleri önceki periyot ile yaklaşık olarak aynıdır.

Her bir istasyonda yapılan taramalar iteratif en yakın nokta algoritması (ICP) (Bes1 1992) ve Polyworks IMAlign modülü ile birleştirilmiştir. Birleştirmelerden önce ICP algoritmasının hızlı çalışması ve dönüşüm matrisinin hesaplanması için yamaçlarda belirlenen doğal noktalar seçilerek ön-birleştirme işlemi yapılmıştır (Şekil 4). 
Birleştirmelerde karesel ortalama hatalar farklı bindirme bölgelerinde değişiklik göstermesine rağmen $\pm 3-5 \mathrm{~cm}$ doğruluğunda birleştirilmiştir.

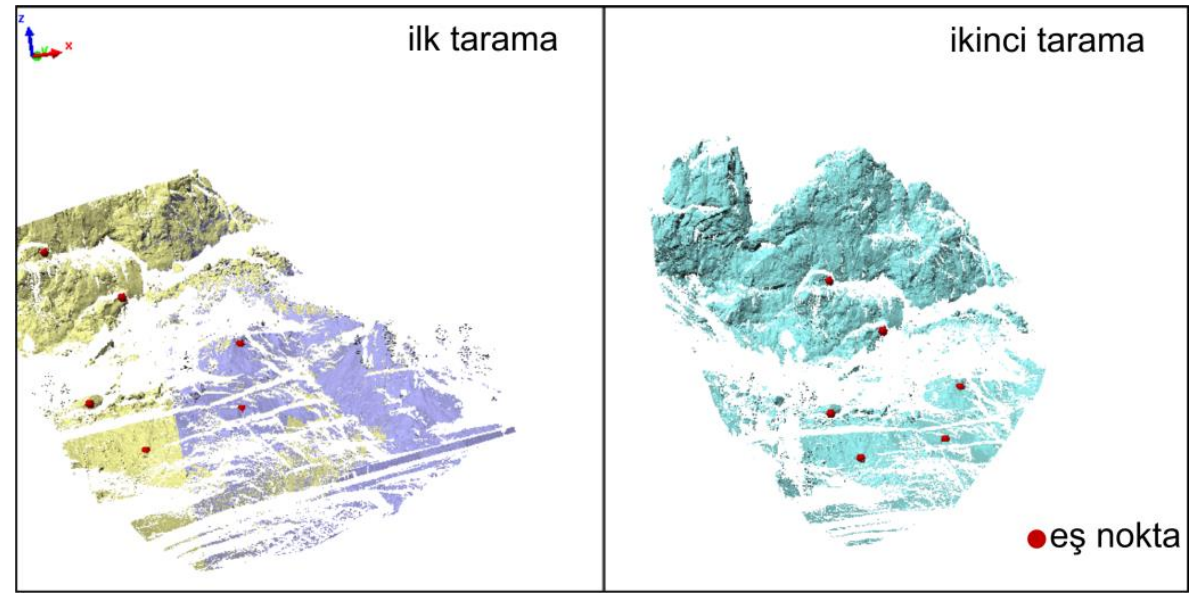

Şekil 4: ICP algoritması öncesi, ön-birleştirme aşaması

\subsection{Yer Kontrol Noktalarının Değerlendirilmesi ve Dönüşüm Parametrelerinin Hesaplanması}

Yersel lazer tarama sistemleri nokta koordinatlarını kendi eksenlerinin başlangıçlarını referans alarak mesafe ve açı ölçüleriyle kartezyen (X,Y,Z) koordinat sisteminde üretirler. Deformasyon izleme çalışmaları için bu koordinat sistemlerinin ortak bir datumda olmaları gerekir. Bu nedenle nokta bulutları belirli yer kontrol noktaları (YKN) ile ortak referans koordinat sistemine getirilir. Bunun için 3B'lu benzerlik dönüşümünün uygulanması gerekir. Bununla ilgili iki durum söz konusudur. Öncelikle koordinat dönüşüm parametrelerinin belirlenmesi ve tüm nokta bulutlarına bu dönüşümün uygulanmasıdır. Dönüşüm modellerinde tarama cihazının aynı ölçek faktörü ile 1şın göndermesi ve birimlerinde değişim olmadığ için ölçek faktörü uygulanmaz ve katı (Rigid) dönüşüm modeli uygulanır.

Proje alanında nokta dönüşümleri için levhalar kullanılmıştır. Bunun sayesinde nokta temelli kayıt ve dönüşüm işlemi gerçekleştirilmiştir. Dairesel levhaların orta noktaları manuel olarak seçilerek dönüşüm uygulanmıştır. Günümüzde farklı algoritmalar sayesinde nokta dönüşümlerinin yanı sıra özellik çıkarımı yapılarak küre, silindir gibi geometrik objeler yardımıyla da dönüşüm uygulanmaktadır.

Yansıtıcı yüzeyler içeren retro-reflector özelliğe sahip hedef sistemleri sinyallerin geri dönüş gücünü artırdığ için nokta bulutlarının yoğunluğu yer kontrol noktasının daha belirgin olmasını sağlamaktadır. Dönüşüm parametre kestirimi için ideal olarak 6 parametre bulunmaktadır. Daha fazla nokta kullanılarak yüksek doğruluk değeri elde edilebilir. Bunun için Gauss-Markov modeli ile en küçük kareler çözümü uygulanır. YKN noktaları gerçek zamanlı kinematik (RTK-GNSS) yöntemi kullanılarak, bir saniyelik veri aralı̆̆ında ve her noktada toplam 30 saniye ölçülmüştür. Nokta koordinatları uluslararası yersel referans ağı (ITRF-96) 2005.00 referans epoğunda, 33 dilim orta meridyeni ve üç derecelik Transversal Mercator (TM33) projeksiyon sisteminde hesaplanmıştır. Jeodezik enlem ve boylam ile elipsoidal yükseklik bilgileri GRS-80 elipsoidine göre tanımlanmıştır. Ölçme sonrası gerekli anten düzeltmeleri ve gerekli düzeltmelerden sonra (Şekil 5a) referanslandırma için $t x t$ uzantılı formatta saklanmıştır.
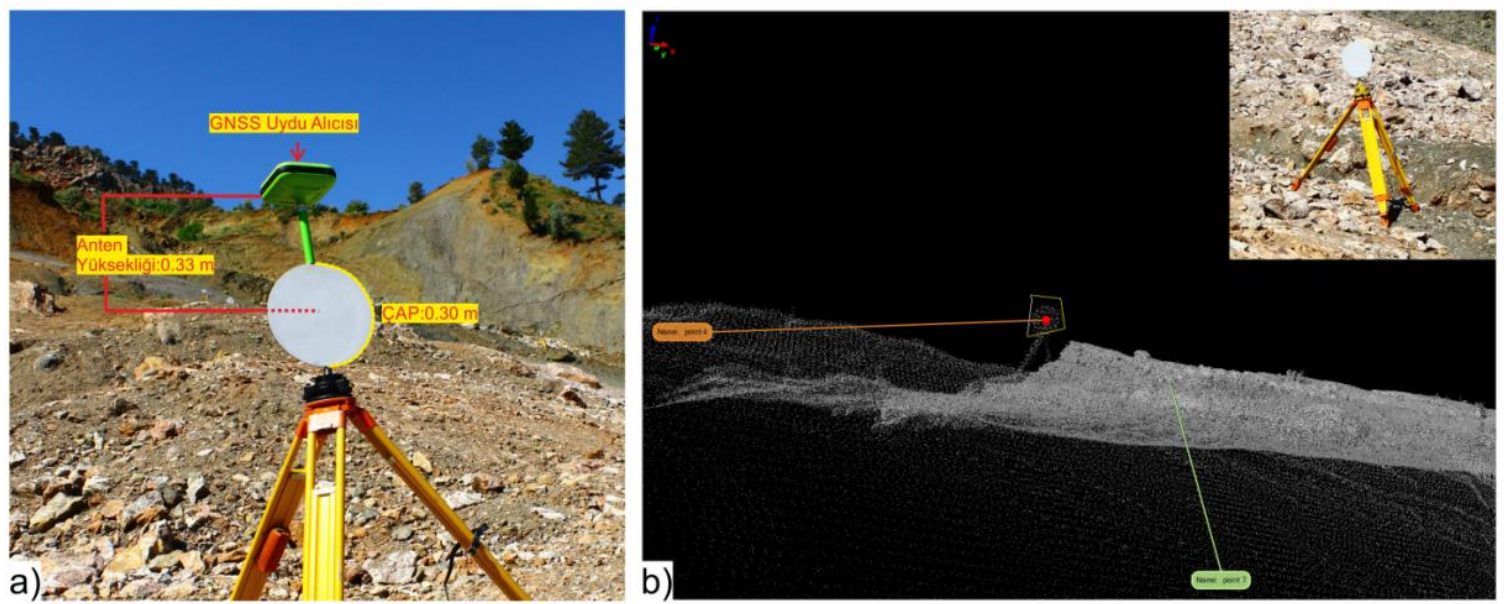

Şekil 5: Yer Kontrol Noktaları (YKN) yapay hedefler ve GNSS entegrasyonu, a) yükseklik değerleri, b) YKN nokta bulutları içinde belirlenmesi (Zeybek 2013) 
Manuel olarak nokta bulutları içinden ortalama nokta koordinatlarıyla dairesel levhanın orta noktasının koordinatları hesaplanmış ve gerçek jeodezik koordinatlarıyla nokta dönüşümlerine tabi tutulmuştur (Şekil 5b).

\subsection{Nokta bulutlarının Filtrelenmesi ve Uyuşumsuz Noktaların Silinmesi}

Nokta bulutları üzerinden bilgi edinmek ve SYM oluşturmak için ilk adım nokta bulutları içinden yalın yeryüzünün çıkarılması ve nokta bulutlarının gruplandırılmasıdır. Bu bölümde farklı filtreleme algoritmalarından bahsedilerek yersel lazer tarama ile elde edilen nokta bulutlarının filtrelenmesi üzerine yapılan araştırmalar irdelenmiştir.

Günümüzde hava LiDAR ile çoklu sinyal gönderilerek yalın yeryüzünün filtrelenmesi oldukça kolaylaştırılmıştır. Fakat yersel lazer taramalar için tek sinyal gönderen cihazlarda bu mümkün olmamaktadır. Bu nedenle filtreleme işlemlerine tabi tutulmaları gerekir. Morfolojik filtreleme, ilerleyen sıklaştırma, yüzey-temelli filtreleme, bölümlemetemelli filtreleme vb. pek çok filtreleme metotları geliştirilmiştir. Bu makalede ilerleyen morfolojik filtreleme (IMF) algoritması kullanılmıştır (Zhang vd. 2003).

\subsection{Sayısal Yükseklik Modellerinin Üretilmesi}

SYM üretilmesi yamaçların ve heyelan bölgesinin morfolojik özelliklerinin çıkarılması ve tanımlanmasına yardımcı olmaktadır. Ayrıca farklı dönemlerde elde edilen SYM'ler karşılaştırılarak heyelanın meydana getirdiği deformasyonların izlenmesinde önemli rol almaktadır. Modellerin üretimi için kullanılacak kaynaklar günümüzde geleneksel ve modern teknolojik verilerle sağlanabilmektedir. Geleneksel yöntemler olan total station, GNSS ve nivelman teknikleri heyelanların zor ve karmaşık yapılarında, zaman kaybı, nokta sıklığının azlığı ve yaşam tehlikesi gibi kullanım zorluklarından dolayı tercih edilmemektedir. Bu nedenle modern teknolojilerin kullanımı yaygınlaşmıştır. Uydu, lidar, insansız hava araçları (IHA) gibi modern teknolojiler haritalama ve deformasyon izleme amacıyla kullanılabilmektedir.

$\mathrm{Bu}$ çalışmada yersel lazer tarama ve GNSS tekniği birlikte kullanılarak topoğrafik modellerin oluşturulması sağlanmıştır. Çalışmanın esas amacı yer üstünde bulunan nesnelerin heyelan analizine etkisinin araştırılması için öncelikle ham veriler üzerinden ters mesafe ağırlıklandırma (inverse distance weighting:IDW) enterpolasyonu uygulayarak SYM elde etmektir.

Basit gösterimi ile IDW enterpolasyonu Shepard metodu olarak adlandırılır ve ağırlık fonksiyonunu kullanır (1). Enterpolasyon gözlemlerinin mesafelerine göre kestirim değerinin katkısının belirlenmesi temeline dayanır. Diğer bir deyişle bilinen noktanın bilinmeyen noktaya olan ilişkisini ve etkisini kestirimidir. Uyuşumsuz ölçülere hassas bir tekniktir.

$$
\begin{aligned}
& w_{i}=\frac{s_{i}^{-p}}{\sum_{j=0}^{n} s_{j}^{-p}} \\
& s_{i}=\sqrt{\left(x-x_{i}\right)^{2}+\left(y-y_{i}\right)^{2}}
\end{aligned}
$$

Burada $p$ keyfi pozitif gerçek sayı, parametrenin kuvveti ve $S_{i}$ enterpolasyon noktasına olan mesafedir.

\section{Bulgular ve Tartışma}

Karşılaştırma ve filtreleme analizleri öncesinde yer kontrol noktaları jeodezik yer koordinatlarına getirilmiştir. Bu bölümde uygulanan dönüşüm Tablo 1 ve Tablo 2 'de gösterilmiştir.

Yer kontrol noktası olarak her iki periyot için 7 adet nokta kullanılmıştır. Bu noktaların karesel ortalama hataları incelendiğinde $\pm 2 \mathrm{~cm}$ doğruluk değerlerine sahiptir ve sonuç olarak yüksek doğrulukta dönüşümler nokta bulutlarına uygulanmıştır. Burada oluşan hataların en genel sebebi, çözünürlük, levhaların tarama merkezine uzaklığı ve yansıyan yüzey noktalarının barındırdığı hatalardan kaynaklanmaktadır. Ham nokta merkez koordinatlarına GNSS ölçülerinden elde edilen koordinatlar dönüşüm matrisi uygulanarak nokta bulutlarına rotasyon otomatik olarak tanımlanmıştır. Ham nokta koordinatları ise yaklaşık lokal koordinatlar olarak girilmiştir. Bu noktalar ile nokta koordinatlarına ortalama ağırlık merkezine dönüşümü (Huge dönüşümü) Polyworks yazılımıyla uygulanmıştır. Bu sayede yüksek doğruluk değerleri elde edilebilmiştir.

Yapılan analiz sonuçlarına göre SYM fark analizlerinde ağaç ve filtreleme yapılmadan yapılan analizlerde deformasyon fazla olmasına rağmen filtrelenmiş sonuçlarda en yüksek deformasyon miktarı belirlenmiştir. İMF algoritması ile ilk periyot filtreleme parametreleri, nokta bulutları kütüphanesi (PCL) yararlanılarak filtreleme yapılmadan önce pencere genişliği $10 \mathrm{~m}$, eğim parametresi 1 , başlangıç mesafesi $0.2 \mathrm{~m}$ ve en uzun mesafe $10 \mathrm{~m}$ 
parametrelerine göre değerlendirilmiştir (Rusu ve Cousins 2011). Analiz süresi 16 saat sürmüştür. Analiz 8 gb Ram a sahip dizüstü bilgisayarda yapılmıştır. İlk periyot filtrelemede filtreleme öncesi 12344096 nokta, yer nokta bulutları 6865348 nokta, nesne nokta bulutları 5478748 nokta gruplarına ayrılmıştır (Şekil 6). İkinci periyot filtrelemede filtreleme öncesi nokta, yer nokta bulutları 15586082 nokta, nesne nokta bulutları 10909883 nokta gruplarına ayrılmıştır.

Tablo 1: Sıfırıncı (ilk-referans) periyot YKN jeodezik referanslandırma sonuçları

\begin{tabular}{|c|c|c|c|c|c|c|c|}
\hline $\begin{array}{l}\text { En büyük } \\
\text { hata }(\mathrm{m})\end{array}$ & 0.082 & $\begin{array}{l}\text { En küçük hata } \\
(\mathrm{m})\end{array}$ & 0.021 & $\begin{array}{l}\text { Ortalama hata } \\
\qquad(\mathrm{m})\end{array}$ & 0.040 & $\begin{array}{l}\text { Standart sapma } \\
\text { (RMS) }\end{array}$ & 0.021 \\
\hline $\begin{array}{l}\text { Nokta } \\
\text { isimleri }\end{array}$ & $\begin{array}{l}\text { Ham nokta } \\
\text { (x) }\end{array}$ & $\begin{array}{l}\text { Ham nokta } \\
\text { (y) }\end{array}$ & $\begin{array}{l}\text { Ham nokta } \\
\text { (z) }\end{array}$ & $\begin{array}{c}\text { GNSS Referans } \\
\text { (x) }\end{array}$ & $\begin{array}{c}\text { GNSS Referans } \\
\text { (y) }\end{array}$ & $\begin{array}{l}\text { GNSS Referans } \\
(\mathrm{z})\end{array}$ & $\begin{array}{l}\text { Merkezler arasındaki } \\
\quad \text { farklar }(\mathrm{m})\end{array}$ \\
\hline $\mathrm{T} 1$ & 455742.240 & 4087776.043 & 1458.081 & 455742.264 & 4087776.021 & 1458.053 & 0.042 \\
\hline $\mathrm{T} 2$ & 455714.767 & 4087774.177 & 1457.046 & 455714.785 & 4087774.188 & 1457.041 & 0.021 \\
\hline $\mathrm{T} 3$ & 455677.682 & 4087761.580 & 1463.224 & 455677.660 & 4087761.622 & 1463.205 & 0.051 \\
\hline $\mathrm{T} 4$ & 455697.689 & 4087742.189 & 1470.443 & 455697.672 & 4087742.200 & 1470.450 & 0.0215 \\
\hline T5 & 455725.065 & 4087754.594 & 1466.221 & 455725.080 & 4087754.606 & 1466.250 & 0.034 \\
\hline T6 & 455713.278 & 4087722.686 & 1478.032 & 455713.270 & 4087722.715 & 1478.034 & 0.029 \\
\hline $\mathrm{T} 7$ & 455666.741 & 4087689.220 & 1495.902 & 455666.735 & 4087689.140 & 1495.919 & 0.082 \\
\hline
\end{tabular}

Tablo 2: Ikinci (model) periyot YKN jeodezik referanslandırma sonuçları

\begin{tabular}{|c|c|c|c|c|c|c|c|}
\hline $\begin{array}{l}\text { En büyük hata } \\
(\mathrm{m})\end{array}$ & 0.054 & $\begin{array}{l}\text { En küçük hata } \\
\text { (m) }\end{array}$ & 0.007 & $\begin{array}{l}\text { Ortalama hata } \\
\qquad(\mathrm{m})\end{array}$ & 0.035 & $\begin{array}{l}\text { Standart Sapma } \\
\text { (RMS) }\end{array}$ & 0.016 \\
\hline Nokta isimleri & $\begin{array}{l}\text { Ham nokta } \\
\text { (x) }\end{array}$ & $\begin{array}{l}\text { Ham nokta } \\
\text { (y) }\end{array}$ & $\begin{array}{l}\text { Ham nokta } \\
\text { (z) }\end{array}$ & $\begin{array}{l}\text { GNSS Referans } \\
(\mathrm{x})\end{array}$ & $\begin{array}{l}\text { GNSS Referans } \\
(\mathrm{y})\end{array}$ & $\begin{array}{l}\text { GNSS Referans } \\
\text { (z) }\end{array}$ & $\begin{array}{l}\text { Merkezler arasindaki } \\
\text { farklar }(\mathrm{m})\end{array}$ \\
\hline $\mathrm{T} 1$ & 455756.841 & 4087790.469 & 1452.562 & 455756.817 & 4087790.438 & 1452.563 & 0.040 \\
\hline $\mathrm{T} 2$ & 455711.186 & 4087774.325 & 1457.042 & 455711.228 & 4087774.353 & 1457.055 & 0.051 \\
\hline $\mathrm{T} 3$ & 455673.793 & 4087760.451 & 1464.309 & 455673.771 & 4087760.405 & 1464.327 & 0.054 \\
\hline $\mathrm{T} 4$ & 455672.817 & 4087730.936 & 1475.411 & 455672.793 & 4087730.931 & 1475.402 & 0.026 \\
\hline $\mathrm{T} 5$ & 455683.883 & 4087717.703 & 1482.096 & 455683.902 & 4087717.716 & 1482.081 & 0.027 \\
\hline T6 & 455706.867 & 4087723.301 & 1478.241 & 455706.874 & 4087723.305 & 1478.242 & 0.007 \\
\hline $\mathrm{T} 7$ & 455688.692 & 4087692.246 & 1492.385 & 455688.697 & 4087692.286 & 1492.379 & 0.040 \\
\hline
\end{tabular}




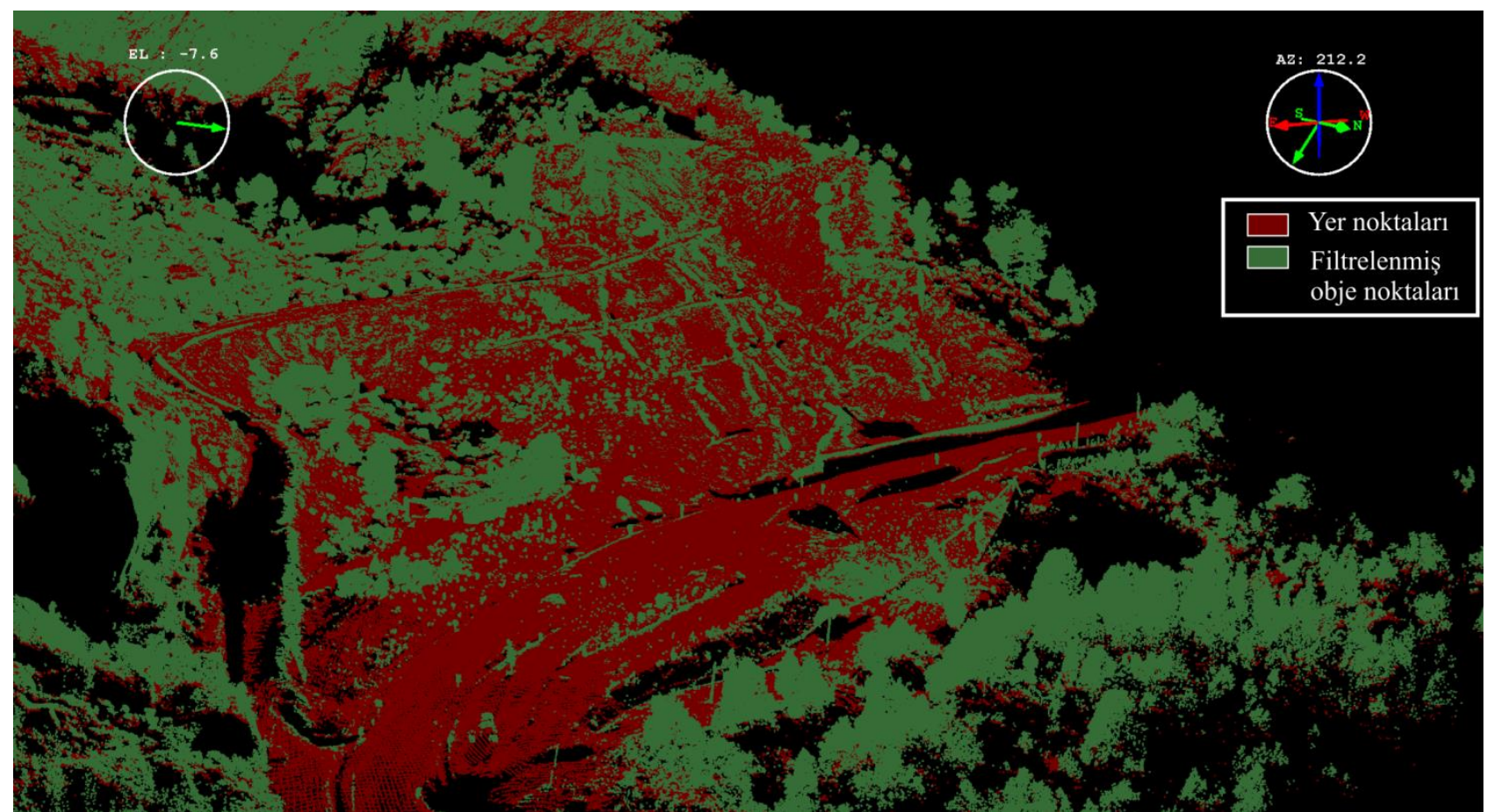

Şekil 6: IMF algoritmasına göre ilk periyot filtreleme sonuçları çalışma bölgesi üzerinden perspektif görünüm

Filtreleme sonuçlarına bakıldığında filtreleme ile çalışma alanında tarama esnasında bulunan araçlar, yol trafik levhaları, ağaçlar, küçük çalılıklar ve küçük yer bitkileri gibi yer üzerinde SYM doğruluğunu etkileyecek nesnelerin başarılı şekilde filtrelenmiştir (Şekil 7).

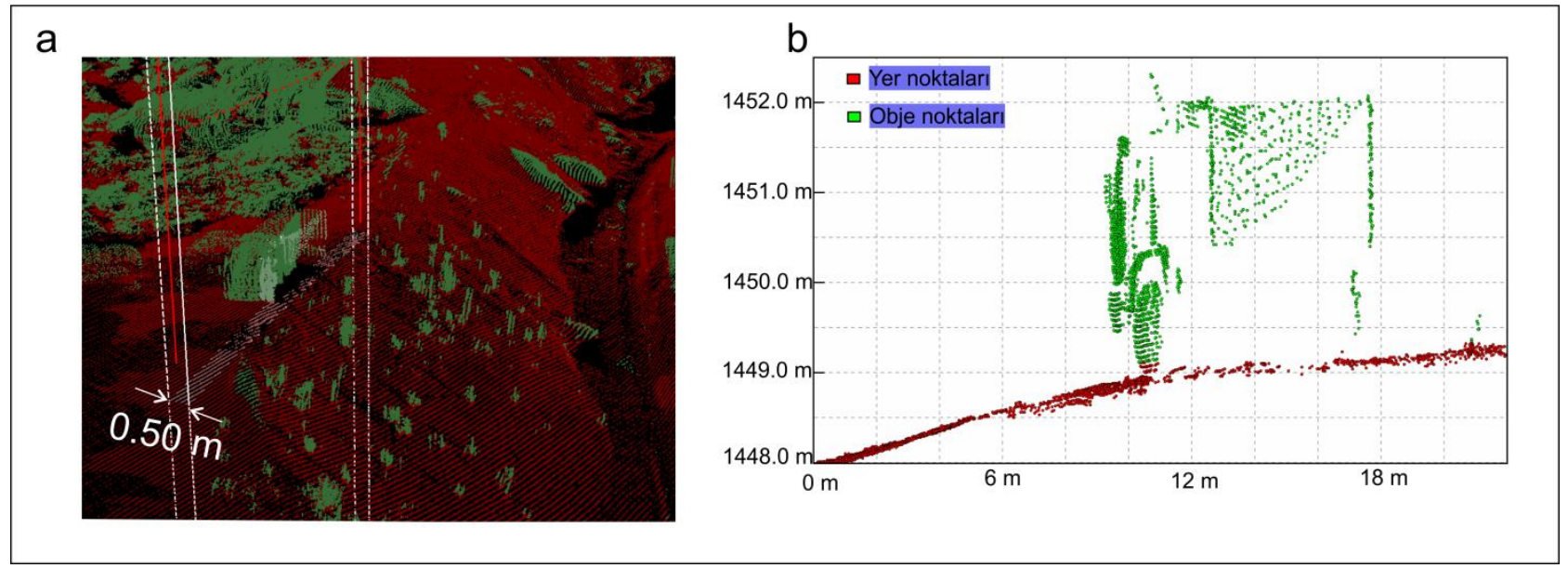

\section{Şekil 7: Filtreleme profil görünümü, a) 0.50 m genişliğinde nokta bulutları içinden görünüm, b) filtreleme sonrası gruplandırılmış nokta bulutları}

Sayısal yüzey modeli ile sayısal yükseklik modelinin farkları alındığında bölgeye ait ağaç yükseklikleri, obje noktalarının analiz edilmesi de kolaylıkla yapılmıştır (Şekil 8 ve Şekil 9). İMF algoritması ile yalnızca yer üzerindeki objeler silinmemekle birlikte ayrıca yersel lazer tarayıcının ürettiği uyuşumsuz ölçmeler de filtrelenmiştir. Bunun yanında atmosferik sis, toz ve atmosferdeki zerreciklere çarpıp geri dönen lazer ışınlarının da filtrelenmesi sayısal modelin doğruluğunu artırmıştır. 

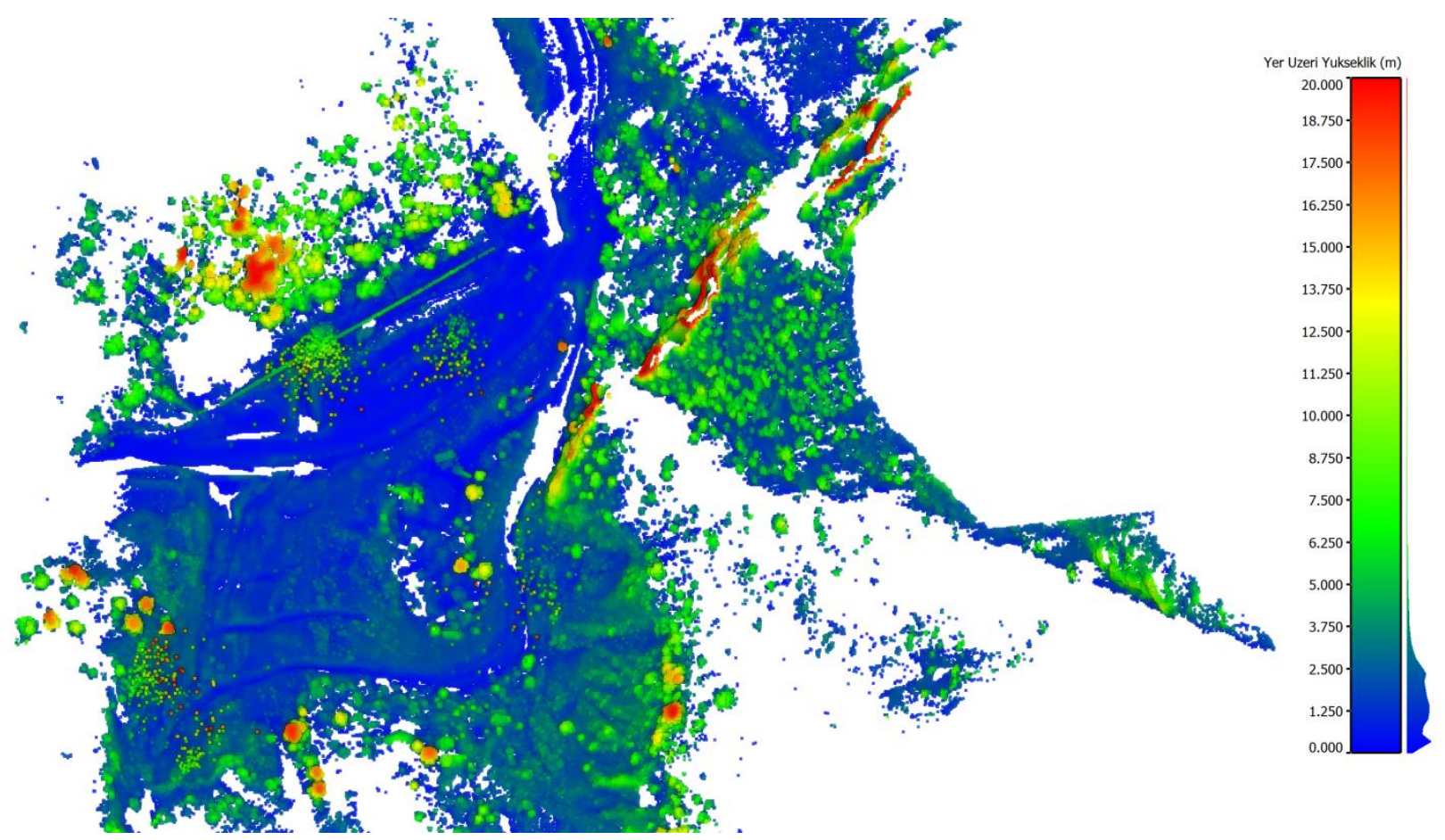

Şekil 8: Sayısal yüzey modeli ile sayısal yükseklik modeli arasındaki farkıııklar

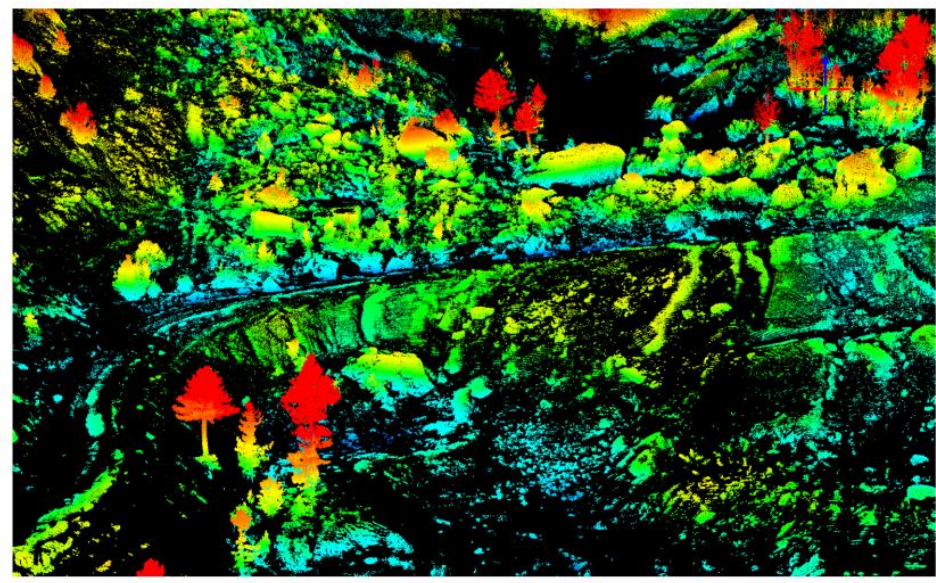

Yer Üzeri Yükseklik (m)

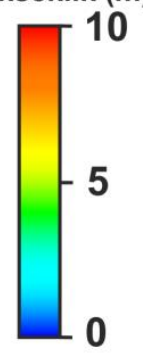

Şekil 9: Ikinci periyot filtrelenmiş obje noktalarının yükseklik değerleri 

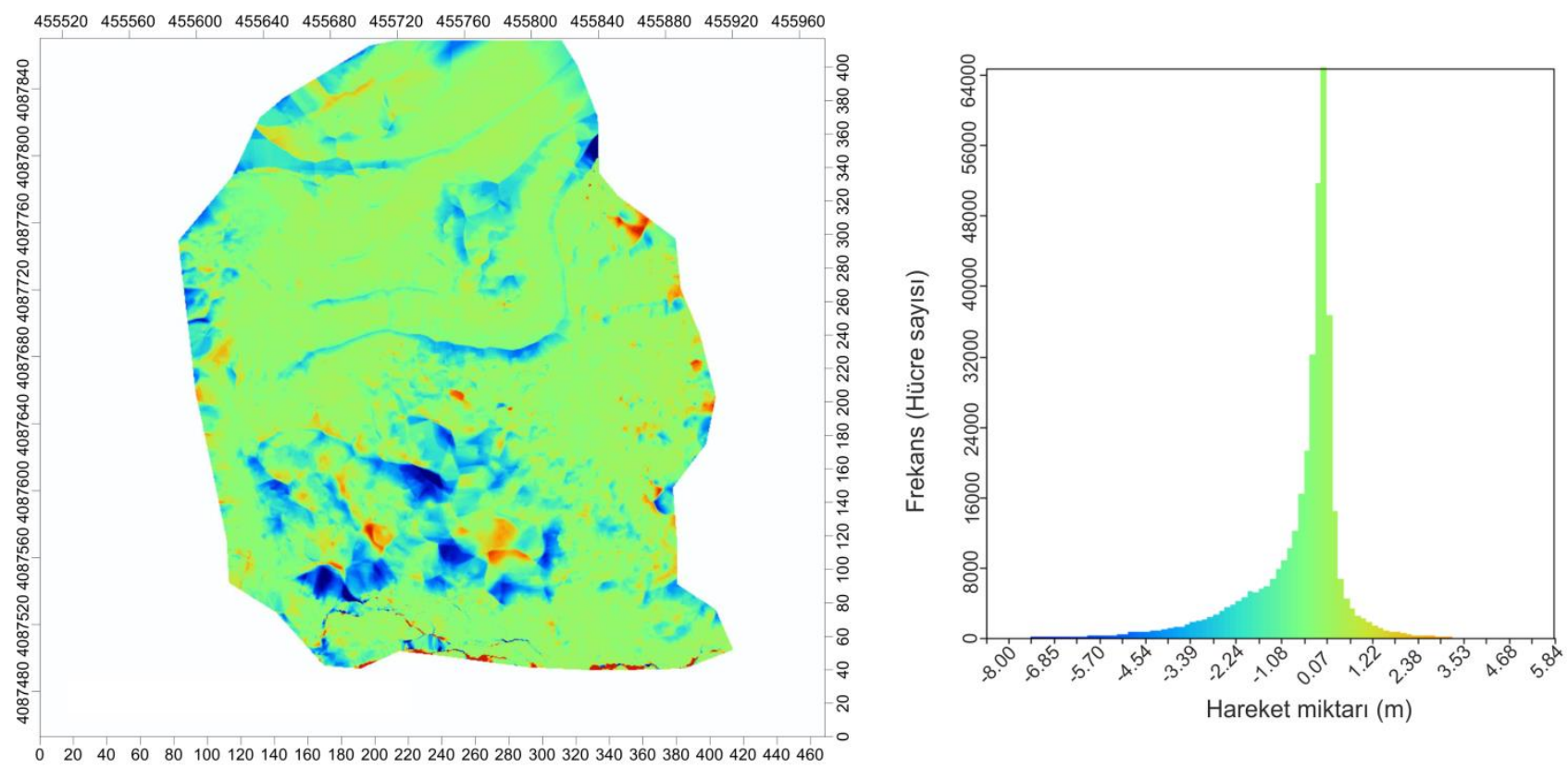

\section{SYM Fark (2-1) (m)}

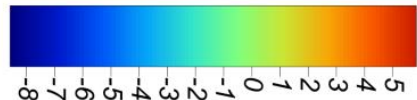

Şekil 10: Ikinci periyot ve ilk periyot arasındaki SYM farkları

(a)

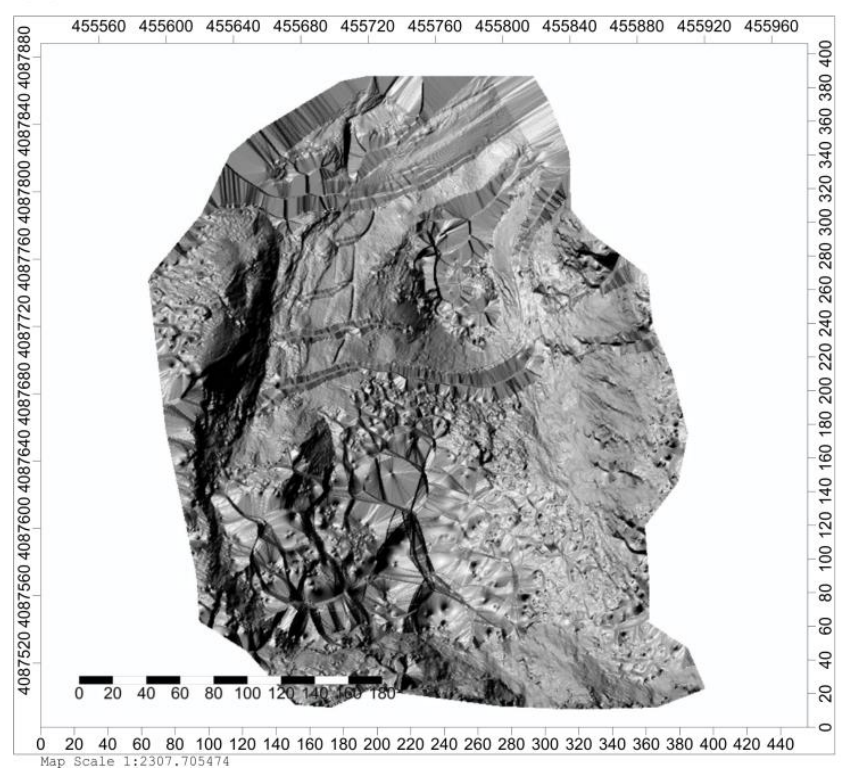

(b)

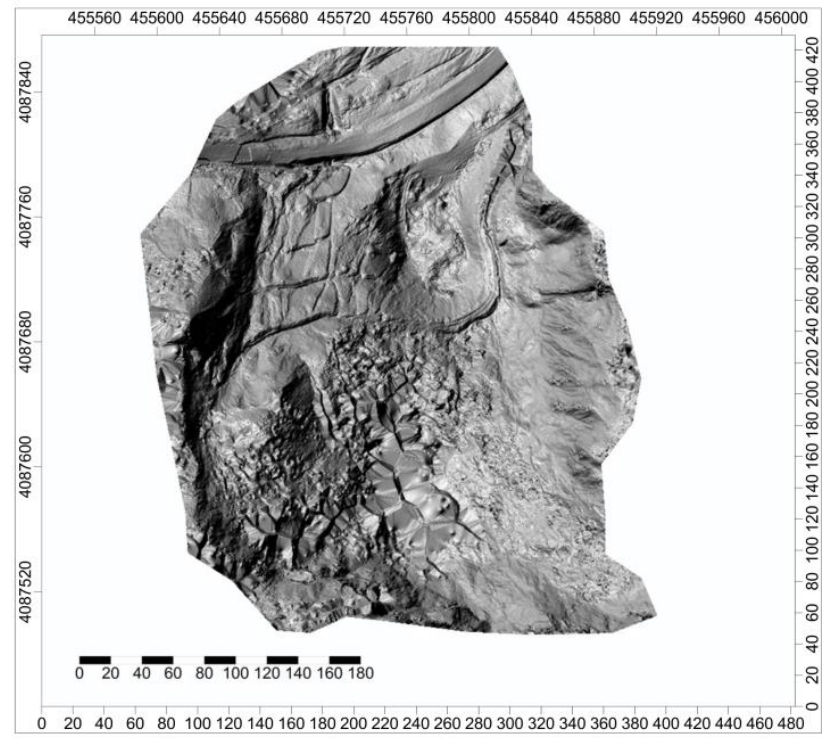

Şekil 11: Analitik hillshade analizi ile sayısal yükseklik modeli detayları

Veri aktarım formatı Las uzantısı programlar arasında kullanılmıştır (http://asprs.org). Yer nokta bulutları ile IDW algoritması ile enterpolasyon uygulanarak SAGA-GIS yazılımında SYM üretilmiştir (Conrad 2006). IDW hücre boyutu (çözünürlüğü) $0.20 \mathrm{~m}$ maksimum nokta arama mesafe $200 \mathrm{~m}$, ağırlıklandırma derecesi 2 alınarak SYM üretilmiştir. SYM'nin yüksek doğrulukta elde edilmesinde en etkili faktörler topografyanın türü, SYM oluşturmanın metodu, grid ağının türü ve SYM çözünürlüğüdür.

Filtreleme uygulaması ile düşük, orta ve yüksek frekanslarda oluşan sistematik, rastgele ve gürültü hatalarından arındırılarak yüksek doğruluklarda SYM üretilmiştir. Doğruluk değerlerinin belirlenmesinde düz arazilerin doğrulukları daha yüksektir. Çalışma bölgesi değerlendirildiğinde yüksek ve eğimli yamaçların doğruluğa etki ettiği gözlenmiştir.

Farklı zamanlarda elde edilen SYM hücresel farkları (Difference of DEM- DoD analizleri) alınarak heyelan bölgesindeki hareket incelemesi yapılmıştır (Şekil 10). Oluşturulan grid alanı $96782 \mathrm{~m}^{2}$ ' dir. En küçük karşılaştırma miktarı -4.66 m, en büyük 1.48 m, ortalama -1.59 m ve standart sapması 1.79 m'dir. SYM karşılaştırmalarında hücresel 
hareketlerin $\mathrm{Z}$ bileşenindeki frekanslarının görüntülenmesi ise ayrıca histogram çıktısı ile incelenmiştir. Bu incelemelerde bölge heyelanının çöküş ortalamasında olduğu yani bölgenin genellikle yükseklik bileşeninde hareket olduğu bu analiz sayesinde ortaya çıkarılmıştır. Ayrıca SYM'lerde detay çıkarımı ve özellik takibi için hillshade (gölgeleme) yapay 1şık görüntüleme analizinden faydalanılmıştır. Analiz parametreleri olarak farklı yöntemler bulunmaktadır. Bu çalışma için standart parametreler uygulanmıştır. Azimuth $315^{\circ}$, yükseklik $45^{\circ}$ ve büyütme faktörü olarak 4 seçilmiştir. Bu analizler sayesinde model kalitesi gözlemlerle sağlanmıştır. Morfolojik filtreleme algoritması bazı alanlarda detay kaybına sebep olmasına rağmen yeryüzü üzerindeki objelerin kolay silinmesine katkıda bulunmuştur (Şekil 11).

\section{Sonuçlar}

Bu çalışmada filtreleme ile elde edilen nokta bulutları ile ham nokta bulutlarının heyelan hareketlerinin izlenmesi ve yorumlanması üzerine iki farklı dönemde elde edilen veriler karşılaştırılmıştır. Yapılan filltreleme ve enterpolasyon analizleri ile ham verilerin işlenmesi, doğrudan karşılaştırılması yerine işlenmiş verilerin karşılaştırılması daha anlamlı ve doğru yorumların yapılması için kolaylıklar sağlamıştır. YLT sayesinde sayısal yüzey modellerinin farklı zamanlarda elde edilmesi ile deformasyon ve heyelan çalışmalarında heyelan hareketleri hakkında önemli bilgiler sağlanmıştır. Bu çalışma ile farklı filtreleme ve enterpolasyon tekniklerinin deformasyon belirlemeler üzerine etkileri incelenmiştir. Jeodezik teknikler heyelan için yapılan yorumların ve daha doğru kararların verilmesinde önemli rol oynamaktadır. Bu araştırma ayrıca YLT tekniğinin heyelan hareketlerinin belirlenmesinde önemli bir teknik olduğunu ve faydalı olduğunu göstermiştir. Heyelan çalışmalarında yeni bir teknik olan yersel lazer tarama teknikleri gelecek çalışmalarda aydınlatıcı, yüksek doğruluk ve yüksek çözünürlükte veri sağlaması ile gerçek yeryüzünün modellenmesine büyük katkı sağlayacaktır.

\section{Teşekkür}

Bu çalışmada TÜBİTAK (Proje no: 111Y307), Selçuk Üniversitesi Bilimsel araştırma projeleri (BAP) (Proje no: 11101028 ve 15401017) kurumlarının proje destek ve kaynakları kullanılmıştır. Ayrıca yazarlar Lancaster Üniversitesi Çevre Araştırma merkezi öğretim üyesi Mike R. James'e konu üzerinde yapılan tartışma ve yorumlarından dolayı teşekkür ediyoruz.

\section{Kaynaklar}

Barbarella M., Fiani M., (2013), Monitoring of large landslides by Terrestrial Laser Scanning techniques: field data collection and processing, Eur J Remote Sens, 46, 126-151.

Besl P.J., McKay N.D., (1992), A method for registration of 3-D shapes, IEEE Trans Pattern Anal Mach Intell, 14(2), $239-256$.

Brodu N., Lague D., (2012), 3D terrestrial lidar data classification of complex natural scenes using a multi-scale dimensionality criterion: Applications in geomorphology, ISPRS Journal of Photogrammetry and Remote Sensing, 68, 121-134.

Conrad O., (2006), SAGA--program structure and current state of implementation, SAGA--analysis and modelling applications'in içinde, (Böhner J., McCloy K.R., Strobl J., Ed.), Verlag Erich Goltze GmbH, Germany, ss.39-52.

James L.A., Watson D.G., Hansen W.F., (2007), Using LiDAR data to map gullies and headwater streams under forest canopy: South Carolina, USA, Catena, 71(1), 132-144.

Kasperski J., Delacourt C., Allemand P., Potherat P., Jaud M., Varrel E., (2010), Application of a Terrestrial Laser Scanner (TLS) to the Study of the Séchilienne Landslide (Isère, France), Remote Sens, 2(12), 2785-2802.

Oppikofer T., Bunkholt H.S.S., Fischer L., Saintot A., Hermanns R.L., (2012), Investigation and monitoring of rock slope instabilities in Norway by terrestrial laser scanning, Taylor Francis Group, London, ss.1235-1241.

Pirotti F., Grigolato S., Lingua E., Sitzia T., Tarolli P., (2012), Laser Scanner Applications in Forest and Environmental Sciences, Ital J Remote Sens, 44(1), 109-123.

Rusu B.R., Cousins S., (2011), 3D is here: Point Cloud Library (PCL), IEEE International Conference on Robotics and Automation (ICRA), 9-13 May, Shanghai, China.

Vosselman G., Maas H.G., (2010), Airborne and Terrestrial Laser Scanning, Whittles Publishing.

Zeybek M., (2013), Heyelanların İlenmesinde Yersel Lazer Tarama ve GNSS Tekniklerinin Birlikte Kullanılması, Selçuk Üniversitesi Fen Bilimleri Enstitüsü, Konya.

Zeybek M., Sanlioglu İ., (2015), Accurate determination of the Taskent (Konya, Turkey) landslide using a long-range terrestrial laser scanner, Bulletin of Engineering Geology and the Environment, 74(1), 61-76.

Zeybek M., Şanlıŏlu İ., Özdemir A., (2015), Monitoring landslides with geophysical and geodetic observations, Environ Earth Sci, doi: 10.1007/s12665-015-4650-x.

Zhang K.Q., Chen S.C., Whitman D., Shyu M.L., Yan J.H., Zhang C.C., (2003), A progressive morphological filter for removing nonground measurements from airborne LIDAR data, Ieee Transactions on Geoscience and Remote Sensing, 41(4), 872-882. 